\title{
USE OF AHP-BASED CLUSTERING ANALYSIS FOR EVALUATING CITIES IN TURKEY ACCORDING TO CONSUMPTION EXPENDITURES
}

\section{ABSTRACT}

Purpose: The purpose of this study is to classify the cities of Turkey with regard to their consumption expenses. Thus, it is ensured to group the cities together whose consumption expenses are similar to each other. In this manner, the concerned people can get information about the socio-economic circumstances and standard of living of these cities. Through this information it's enabled to study devoted to satisfying the needs of society.

Technique: This study has got four stages.

Fist stage: This is the stage which statistics are collected. The statistics are obtained from Turkey Statistical Institute (TSI) web site and they involves the years 2012-2014. The cities in Turkey are examined with regard to their consumption expenses on the basis of Nomenclature of Territorial Units for Statistics-2 (NUTS). It is seen that these statistics consists of 9 criterions. They are specified below.

- Food and non-alcoholic beverages

- Alcoholic beverages, cigarette and tobacco

- Clothing and footwear

- Housing and rent

- Furniture, houses appliances and home care services

- Health

- Transportation

- Communication

- Education Services

Second stage: In this stage, the 9 criterions specified in the first stage are examined through Analytic Hierarchy Process (AHP), which is one of the multiple-criteria decision analysis techniques. A comparison matrix is formed for these 9 criterions by seeking the expert opinion from three academicians who study in engineering field. The numerical value of matrix is obtained by having a geometric average of expert assessments. "Expert Choice" program improved for AHP is used in practice. The comparison matrix which is formed based on the expert opinions is entered into the program and calculated the matrix consistency rate as 0,02 . Because this rate is under 0,10 , it is seen that the comparison matrix which is formed is consistent. The criterions under $\% 10$ are eliminated. At last, it's decided to use 5 criterions below in the study.

They are:

- Food and Non-Alcoholic Beverages

- Clothing and footwear

- Housing and rent

- Transportation

- Education Services 
- Third stage: Clustering is made in this stage. Cluster analysis technique from Data Mining techniques is used for it and taken advantage of k-means algorithm. SPSS Clementine program is used in practice. Because there are 7 regions in Turkey, the number of cluster is specified as $7(k=7)$. So, it's enabled to form 7 clusters.

Fourth stage: In this stage, the study is ended by interpreting the results obtained.

Evidences: In consequence of the study, seven clusters are obtained. One of these clusters originates from İstanbul, Ankara, and İzmir which are the most developed cities of Turkey. The other 3 clusters originate from the cities which have borders to each others. The other 3 clusters originate from the cities which have borders to each others on a large scale. It is thought that the cities in the same cluster make consumption expense similar amount to each other in terms of consumption expenses. Because of that, when the first cluster is examined, it is determined that 3 most developed cities of Turkey make consumption expense similar amount to each other. The cities which are the elements of other 6 clusters similarly make consumption expense similar amount to each other, too. These 6 cluster's common feature is that they originate from the cities which have borders to each others on a large scale.

Result: In this study, it is determined consumption expenses criteria through AHP by taking expert opinion and the cities are clustered according to the criterions specified by clustering analysis technique from Data Mining techniques. In other studies in future, different results may be obtained by specifying different criterions, by taking opinions from different experts. In this study, the cities in Turkey are examined by separating 26 regions on the basis of Statistical Classification of Territorial Units-2 (SCTU-2). In other studies in future, analyzable studies can be done on the basis of 81 cities. While k-means algorithm is used in this study, because there are 7 geographic regions in Turkey, 7 clusters are obtained. In future studies the number of cluster can be changed considering different criteria. 